Article

\title{
Poly(3-hydroxybutyrate) Modified by Plasma and TEMPO-Oxidized Celluloses
}

\author{
Denis Mihaela Panaitescu $1, * \mathbb{D}$, Sorin Vizireanu ${ }^{2, *} \mathbb{D}$, Sergiu Alexandru Stoian ${ }^{1,3}$, \\ Cristian-Andi Nicolae ${ }^{1}$, Augusta Raluca Gabor ${ }^{1}$, Celina Maria Damian ${ }^{3}$, Roxana Trusca ${ }^{4}$, \\ Lavinia Gabriela Carpen ${ }^{2,5}$ and Gheorghe Dinescu ${ }^{2,5}$ (D)
}

1 Polymer Department, National Institute for Research and Development in Chemistry and Petrochemistry, 202 Spl. Independentei, 060021 Bucharest, Romania; stoian.sergiu@gmail.com (S.A.S.);

ca_nicolae@yahoo.com (C.-A.N.); ralucagabor@yahoo.com (A.R.G.)

2 National Institute for Laser, Plasma and Radiation Physics, Atomistilor 409, Magurele-Bucharest, 077125 Ilfov, Romania; lavinia.carpen@infim.ro (L.G.C.); dinescug@infim.ro (G.D.)

3 Advanced Polymers Materials Group, University Politehnica of Bucharest, 1-7 Polizu Street, 011061 Bucharest, Romania; c.damian@tsocm.pub.ro

4 Science and Engineering of Oxide Materials and Nanomaterials, University Politehnica of Bucharest, 1-7 Gh. Polizu Street, 011061 Bucharest, Romania; truscaroxana@yahoo.com

5 Faculty of Physics, Bucharest University, 405 Atomistilor Street, Magurele-Bucharest, 077125 Ilfov, Romania

* Correspondence: panaitescu@icechim.ro (D.M.P.); s_vizi@infim.ro (S.V.)

Received: 22 June 2020; Accepted: 6 July 2020; Published: 7 July 2020

check for updates

\begin{abstract}
Microcrystalline cellulose (MCC) was surface modified by two approaches, namely a plasma treatment in liquid using a Y-shaped tube for oxygen flow (MCC-P) and a TEMPO mediated oxidation (MCC-T). Both treatments led to the surface functionalization of cellulose as illustrated by FTIR and XPS results. However, TEMPO oxidation had a much stronger oxidizing effect, leading to a decrease of the thermal stability of MCC by $80^{\circ} \mathrm{C}$. Plasma and TEMPO modified celluloses were incorporated in a poly(3-hydroxybutyrate) (PHB) matrix and they influenced the morphology, thermal, and mechanical properties of the composites (PHB-MCC-P and PHB-MCC-T) differently. However, both treatments were efficient in improving the fiber-polymer interface and the mechanical properties, with an increase of the storage modulus of composites by 184\% for PHB-MCC-P and 167\% for PHB-MCC-T at room temperature. The highest increase of the mechanical properties was observed in the composite containing plasma modified cellulose although TEMPO oxidation induced a much stronger surface modification of cellulose. This was due to the adverse effect of more advanced degradation in this last case. The results showed that Y-shaped plasma jet oxidation of cellulose water suspensions is a simple and cheap treatment and a promising method of cellulose functionalization for PHB and other biopolymer reinforcements.
\end{abstract}

Keywords: cellulose; plasma in liquids; polyhydroxyalkanoate; polymer composites; thermal properties; DMA

\section{Introduction}

Biopolymers are seen as a viable alternative to synthetic polymers in many applications and they are unparalleled in the medical field [1-3]. Poly(3-hydroxybutyrate) (PHB) is an aliphatic polyester obtained by microbial synthesis and, for the moment, is the most affordable of polyhydroxyalkanoates (PHAs) family. The known shortcomings of PHB are the high cost and brittleness along with the low thermal stability during melt processing [4,5]. Adding plasticizers, elastomers, and organic or inorganic fillers are the most used strategies to improve PHB properties [6-8]. Among the fillers, microand nano-celluloses were most intensely studied to modify PHB and other aliphatic polyesters [9-12]. 
Microfibrillated cellulose is obtained from cellulose, a sustainable and low-cost naturally occurring biopolymer. This is the most abundant organic polymer on Earth and comprises $33 \%$ of all the plants on the planet $[13,14]$. Microfibrillated cellulose is biodegradable and biocompatible and has reduced carbon dioxide emissions in the environment. It shows an adaptable surface chemistry and a unique spectrum of properties: high water-uptake capability, low density, high crystallinity and Young's modulus, and good thermal stability [12-14]. The research, production, and application of microfibrillated cellulose have experienced a real boost in the last twenty years. It can be extracted from a multitude of sources, such as wood, plants, algae, by-products, and waste of the agro-food industry by mechanical disintegration [13-15]. Refining, homogenization, high power ultrasonication, or microfluidization, with or without additional enzymatic or chemical pretreatments are generally the most used methods to obtain long flexible microfibrils [12-15].

TEMPO-mediated oxidation of cellulose consists of surface oxidation of cellulose in aqueous suspension using sodium hypochlorite as oxidant and 2,2,6,6-tetramethylpiperidine-1-oxyl radical (TEMPO) and sodium bromide as catalysts at an alkaline $\mathrm{pH}$ [16-18]. This pre-treatment proved to be a successful method for ensuring the selective conversion of C6 hydroxyl group of cellulose to carboxylate group. Previous studies have shown the great advantage of this pre-treatment which reduces the energy consumption and the number of cycles in the subsequent stages of mechanical defibrillation [18,19].

Recently, plasma treatment was found to be efficient for the defibrillation and functionalization of cellulose $[20,21]$. Plasma treatment was mainly studied to improve the surface of cellulose textiles or membranes but, in certain conditions, plasma treatment may ensure the defibrillation and chemical functionalization of cellulose [21]. In particular, a plasma torch immersed in the water suspension of cellulose in the presence of different reactive gases induced physical and chemical changes of cellulose [21] and is proposed as an alternative to the mechano-chemical methods usually employed for the modification of cellulose and fabrication of nanocellulose. Moreover, plasma treated cellulose showed a good reinforcing effect in PHB/cellulose composites, increasing both the Young's modulus and tensile strength [21].

Plasma treatment of nanocellulose water suspensions using a filamentary plasma jet based on dielectric barrier discharge (DBD) proved to be very advantageous in the surface functionalization of nanocellulose [20]. Only $0.2 \mathrm{wt} \%$ of filamentary jet plasma functionalized nanocellulose increased the tensile strength and Young's modulus of PHB nanocomposite by $10-15 \%$ compared to the nanocomposite with the same amount of untreated nanocellulose. The surface functionalization of cellulose in water suspensions using DBD plasma is an environmentally friendly, simple, cheap, and low-energy consuming treatment that overcomes the disadvantages of complex, time-consuming, and energy-intensive chemical-mechanical treatments. Moreover, toxic products that must be deactivated are generally released from chemical treatments. However, DBD filamentary plasma sources cannot work with higher fluxes of reactive gases. Our preliminary attempts have shown that a flux of reactive gas $\left(\mathrm{O}_{2}\right.$ or $\left.\mathrm{NH}_{3}\right)$ greater than $20 \mathrm{sccm}\left(3.33 \times 10^{-7}\right.$ standard cubic meter per second $)$ led to the extinction of the discharge submersed in the water suspensions of cellulose. For this reason, in this work, the DBD plasma source was modified for the addition of the reactive gas laterally in the discharge. This new method makes it possible to work with much higher fluxes of oxygen or other reactive gases, even greater than $500 \mathrm{sccm}$.

In this study, a microcrystalline cellulose (MCC) was treated with a filamentary Y-shaped DBD plasma jet generated in argon-oxygen gas mixture and immersed in the liquid suspension of cellulose. For a comparison with chemical treatments, MCC was chemically modified using TEMPO mediated oxidation, an eco-friendlier chemical method compared to acid hydrolysis. The changes induced by the two treatments (plasma and TEMPO) were highlighted by Fourier transform infrared (FTIR) spectroscopy, X-ray photoelectron spectroscopy (XPS), and thermogravimetric analysis (TGA). Plasma and TEMPO modified celluloses (MCC-P and MCC-T) were used to reinforce a PHB matrix and 
the composites were characterized by thermal analyses, dynamic mechanical analysis, and scanning electron microscopy (SEM).

\section{Materials and Methods}

\subsection{Materials}

Microcrystalline cellulose (MCC) was purchased from Sigma-Aldrich (Saint Louis, MO, USA). MCC is rod-shaped and has a mean diameter of $20 \mu \mathrm{m}$, a bulk density of $0.5 \mathrm{~g} / \mathrm{cm}^{3}$ and a small aspect ratio. PHB type P304 from Biomer (Schwalbach am Taunus, Germany) was used to prepare the composites. A tensile strength of $28 \mathrm{MPa}$, determined according to ISO 527:2012 standard with $50 \mathrm{~mm} / \mathrm{min}$ [22], was provided for PHB type P304 by the producer. Acetonitrile 99\% (ACN) purchased from Fluka Chemie AG (Buchs, Switzerland) was used as received. Further, 2,2,6,6-tetramethylpiperidine-1-oxyl radical, 98\% (TEMPO) was purchased from Sigma-Aldrich (Saint Louis, MO, USA), sodium hypochlorite 10\% from Oltchim (Rm-Valcea, Romania), sodium bromide, hydrochloric acid, and sodium hydroxide, all of analytical grade, were obtained from Merck KGaA (Darmstadt, Germany).

\subsection{Plasma Treatment of Cellulose Suspensions}

The cellulose suspension ( $5 \mathrm{wt} \%$ ) was prepared by dispersing $5 \mathrm{~g}$ MCC in $95 \mathrm{~mL}$ of distilled water by ultrasonication using a Elmasonic S $15 \mathrm{H}$ bath (Elma, Singen, Germany) for $1 \mathrm{~h}$. The treatment of MCC suspensions was carried out using a DBD plasma source with floating electrode, coupled with a radiofrequency power supply [23,24]. The discharge tube was modified in a Y-shape geometry (Figure 1). The Y-shaped configuration allows for the introduction of large amounts of reactive gases without extinguishing the discharge.

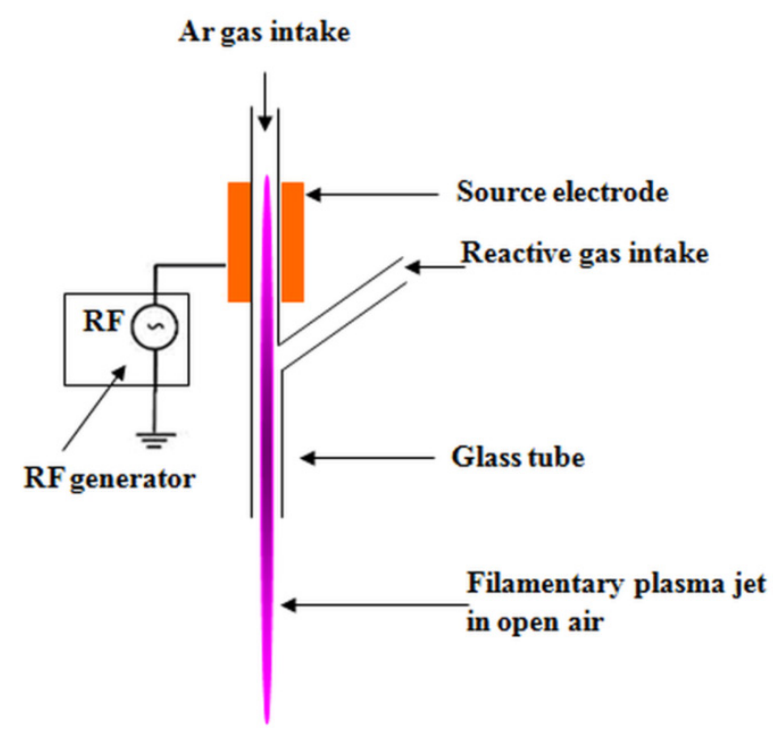

Figure 1. Configuration of the DBD Y-shaped source.

The plasma jet was initiated in argon (RF power $100 \mathrm{~W}$, flow rate $3000 \mathrm{sccm}$ ), in open ambient conditions, and then immersed in the water suspension of MCC. Sccm, standard cubic centimeters per minute, is a measure for the flow rate of particles, $1 \mathrm{sccm}$ denotes that in one minute in the chamber entered a number of particles corresponding to those existing in a volume of 1 cubic centimeter at standard temperature $(273 \mathrm{~K})$ and pressure $(1 \mathrm{~atm})$. An oxygen flux of $500 \mathrm{sccm}$ was introduced through the lateral branch of the Y-tube and the discharge was maintained for $1 \mathrm{~h}$ of treatment. Then, ACN $(30 \%)$ was mixed in the water suspension of MCC for ensuring better conditions for surface functionalization of cellulose and the suspension was plasma treated with Ar for 30 min using the 
same source. Plasma treated MCC suspension was ultrasonicated for $30 \mathrm{~min}$ and then freeze dried for $72 \mathrm{~h}$ using a FreeZone 2.5 L Benchtop Freeze Dry System (Labconco, Kansas City, MO, USA).

\subsection{TEMPO Mediated Oxidation of MCC}

MCC was oxidized using 2,2,6,6-tetramethylpiperidine-1-oxyl radical as a catalyst and sodium hypochlorite as an oxidant. Five grams of MCC were dispersed in $195 \mathrm{~mL}$ of distilled water by magnetic stirring at room temperature for $24 \mathrm{~h}$. TEMPO ( $0.08 \mathrm{~g}$ corresponding to $0.1 \mathrm{mmol} / \mathrm{g}$ cellulose) was dispersed in $100 \mathrm{~mL}$ of distilled water until complete dissolution using an Elmasonic S40 ultrasonic bath (Elma, Germany). Meanwhile, $0.52 \mathrm{~g} \mathrm{NaBr}(1.0 \mathrm{mmol} / \mathrm{g}$ cellulose) were added over the TEMPO solution and dispersed using the same bath. The TEMPO/NaBr solution was added to the cellulose suspension in small portions under magnetic stirring. Then, $10 \% \mathrm{NaClO}$ solution $(29.80 \mathrm{~g}$ corresponding to $8.0 \mathrm{mmol} / \mathrm{g}$ cellulose) was added dropwise for half an hour and stirred for $3 \mathrm{~h}$ from the moment of the first drop of $\mathrm{NaClO}$. The $\mathrm{pH}$ of the solution was kept constant $(\mathrm{pH} 10-11)$ during the reaction by the addition of $1 \mathrm{M}$ solutions of $\mathrm{HCl}$ and $\mathrm{NaOH}$. After the completion of the reaction, the TEMPO treated cellulose suspension was dialyzed using Spectra/Por molecular porous membrane (MWCO $3.5 \mathrm{kDa}$, SpectrumLabs (Rancho Dominguez, CA USA) for removing the unreacted products. After the treatments, the MCC suspension was ultrasonicated for $30 \mathrm{~min}$ and then freeze dried for $72 \mathrm{~h}$ using a FreeZone 2.5 L Benchtop Freeze Dry System (Labconco, Kansas City, MO, USA). Plasma treated and TEMPO oxidized MCC were denoted as MCC-P and MCC-T.

\subsection{Preparation of PHB Composites with Untreated, Plasma and TEMPO Oxidized MCC}

PHB pellets, MCC-P and MCC-T were dried in vacuum ovens at $60^{\circ} \mathrm{C}$ for $4 \mathrm{~h}$. Different treated MCC (2 wt \%) was melt blended with PHB using a Brabender LabStation (Duisburg, Germany) with a mixing chamber of $30 \mathrm{~cm}^{3}$, at $165{ }^{\circ} \mathrm{C}$ for $8 \mathrm{~min}$ at a rotor speed of $50 \mathrm{~min}^{-1}$. For morphological and mechanical characterization, composites sheets of $0.5 \mathrm{~mm}$ in thickness were obtained by compression molding using an electrically heated press (P200E, Dr. Collin, Maitenbeth, Germany). The composites were pressed at $175^{\circ} \mathrm{C}$ for $120 \mathrm{~s}$ preheating (without pressure), $75 \mathrm{~s}$ under pressure (100 bar), and cooling for $1 \mathrm{~min}$ in a cooling cassette. The sheets were kept at room temperature for at least 2 weeks before characterization. PHB composites with untreated MCC, MCC-T, and MCC-P were denoted as PHB-MCC, PHB-MCC-T, and PHB-MCC-P. The schematic representation of operations for obtaining PHB composites with different treated MCC is shown in Figure 2.

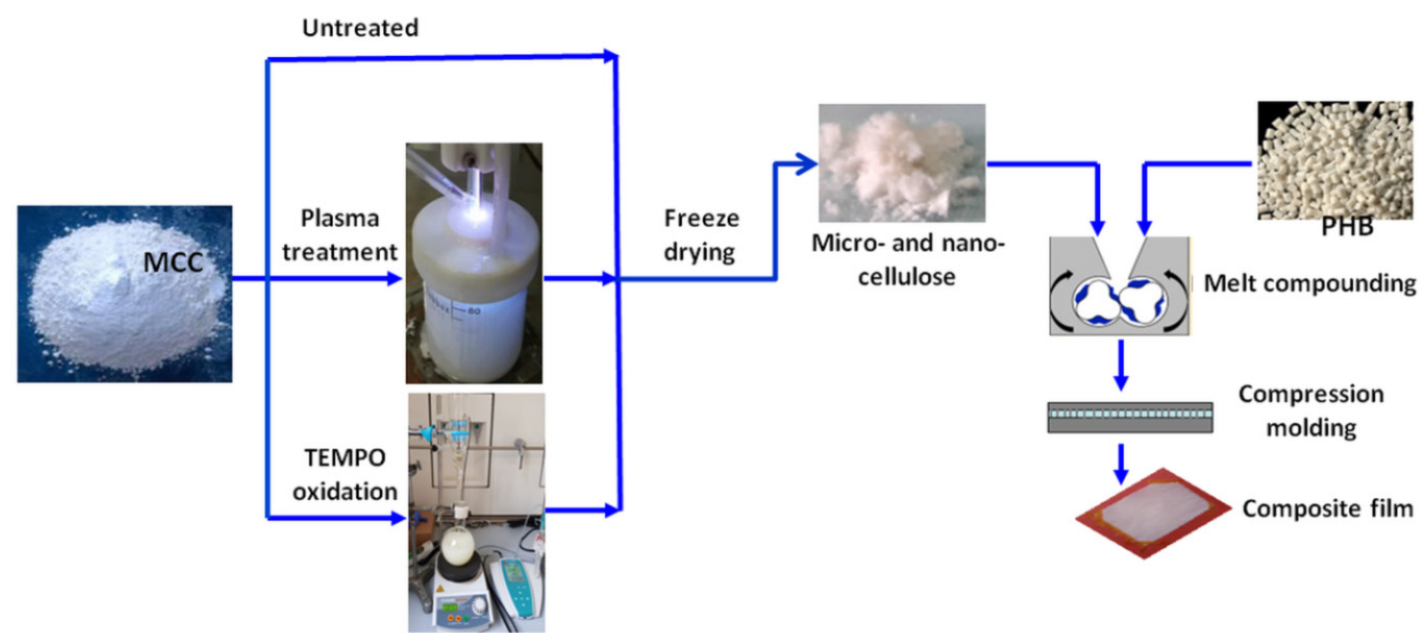

Figure 2. The sequence of main operations for the fabrication of PHB composites with untreated, plasma treated and TEMPO oxidized MCC. 


\subsection{Characterization}

\subsubsection{SEM Investigation}

The compression molded sheets of PHB-MCC composites were fractured in liquid nitrogen and then sputter-coated with a thin layer of gold. The surface of fractured composites was analyzed by SEM using a Quanta Inspect F scanning electron microscope (FEI-Philips, Hillsboro, OR, USA) equipped with a field emission gun. The microscope was operated in high vacuum at $30 \mathrm{kV}$ with a resolution of $1.2 \mathrm{~nm}$.

\subsubsection{Chemical Characterization by FTIR and XPS}

The FTIR spectra of untreated, plasma, and TEMPO treated cellulose were recorded on a Tensor 37 spectrometer from Bruker Optics (Ettlingen, Germany) with an attenuated total reflectance (ATR) accessory. The spectra were collected in duplicate, at room temperature, from 400 to $4000 \mathrm{~cm}^{-1}$, with 16 scans at a resolution of $4 \mathrm{~cm}^{-1}$. Plasma treated and TEMPO oxidized cellulose suspensions were dropwise deposited on silicon wafers and dried several days at room temperature to obtain films. The surface of cellulose films was characterized by X-ray photoelectron spectroscopy (XPS) using ESCALAB $^{\mathrm{TM}}$ XI+ spectrometer (Thermo Scientific, Waltham, MA, USA) with a monochromatic $\mathrm{Al} \mathrm{K} \alpha$ source at $1486.6 \mathrm{eV}$. Both survey spectra (step of $1 \mathrm{eV}$ ) at a pass energy of $100 \mathrm{eV}$ and high-resolution spectra in the $\mathrm{C} 1 \mathrm{~s}$ and $\mathrm{O} 1 \mathrm{~s}$ regions (step of $0.1 \mathrm{eV}$ ) at pass energy of $20 \mathrm{eV}$ were recorded.

\subsubsection{Thermal Characterization}

Thermogravimetric analysis (TGA) was used to characterize the thermal stability of MCC samples before and after the treatments and the thermal behavior of PHB composites with different treated celluloses. TGA was carried out on duplicate cellulose samples sealed in aluminium pans using a SDT Q600 V20.9 (TA Instruments Inc., New Castle, DE, USA) with helium as the purge gas $(100 \mathrm{~mL} / \mathrm{min})$. TGA measurements of PHB composites were carried out on a TGA Q500 V20.10 (TA Instruments Inc., New Castle, DE, USA) in platinum pans, using nitrogen as purge gas at a flow rate of $90 \mathrm{~mL} / \mathrm{min}$. All the samples, celluloses or composites, were heated from 25 to $700^{\circ} \mathrm{C}$ at a heating rate of $10^{\circ} \mathrm{C} / \mathrm{min}$.

\subsubsection{Differential Scanning Calorimetry (DSC)}

DSC measurements were carried out on composites using a DSC Q2000 V24.9 from TA Instruments (New Castle, DE, USA) under helium flow ( $30 \mathrm{~mL} / \mathrm{min}$ ). Samples of 6-7 $\mathrm{mg}$ were heated from 30 to $200{ }^{\circ} \mathrm{C}$ and equilibrated for $3 \mathrm{~min}$ for erasing the thermal history (first heating cycle), cooled down to $-50{ }^{\circ} \mathrm{C}$, isothermal for $2 \mathrm{~min}$ (cooling cycle) and reheated to $200{ }^{\circ} \mathrm{C}$ (second heating cycle). A heating/cooling rate of $10{ }^{\circ} \mathrm{C} / \mathrm{min}$ was used in all cycles. The degree of crystallinity $\left(X_{c}\right)$ was determined from the second heating cycle by dividing the total melting enthalpy $\Delta H_{m}$ (of the peak and shoulder) by the amount of PHB in the composites $\left(W_{P H B}\right)$ and $\Delta H_{0}$, the melting enthalpy of $100 \%$ crystalline PHB (146 J/g [25]):

$$
X_{c}(\%)=\frac{\Delta H_{m}}{\Delta H_{0}} \cdot \frac{100}{W_{P H B}}
$$

\subsubsection{DMA Characterization}

The dynamic mechanical properties of composites were determined using a DMA Q800 (TA Instruments, New Castle, DE, USA) in multi-frequency-strain mode. Bar specimens of $12 \times 6 \times 0.5 \mathrm{~mm}^{3}$ were cut from the composite sheets and cooled to $-35{ }^{\circ} \mathrm{C}$, kept isothermally at this temperature for $5 \mathrm{~min}$, and heated to $165^{\circ} \mathrm{C}$ with a heating rate of $3{ }^{\circ} \mathrm{C} / \mathrm{min}$. Storage modulus, showing the recoverable stored energy and $\tan \delta$ or damping factor, which is the ratio of the loss modulus to the storage modulus, were plotted against temperature. 


\section{Results and Discussion}

\subsection{Characterization of MCC, MCC-P and MCC-T}

The changes induced in cellulose by the two treatments (plasma and TEMPO) were highlighted by TGA, FTIR, and XPS.

\subsubsection{Effect of the Treatments on the Thermal Stability of MCC}

TGA and derivative thermogravimetric (DTG) curves of MCC, MCC-T, and MCC-P are shown in Figure 3. Pure MCC showed one major degradation step with the onset degradation temperature $\left(T_{\text {on }}\right)$ at $309.3{ }^{\circ} \mathrm{C}$ and the temperature of the maximum degradation rate $\left(T_{d}\right)$ at $331.5{ }^{\circ} \mathrm{C}$, similar to other observations [21,26]. The highest loss of weight was noticed between 280 and $360{ }^{\circ} \mathrm{C}$, when the reactions of decomposition, depolymerization, and decarboxylation overlap [26].
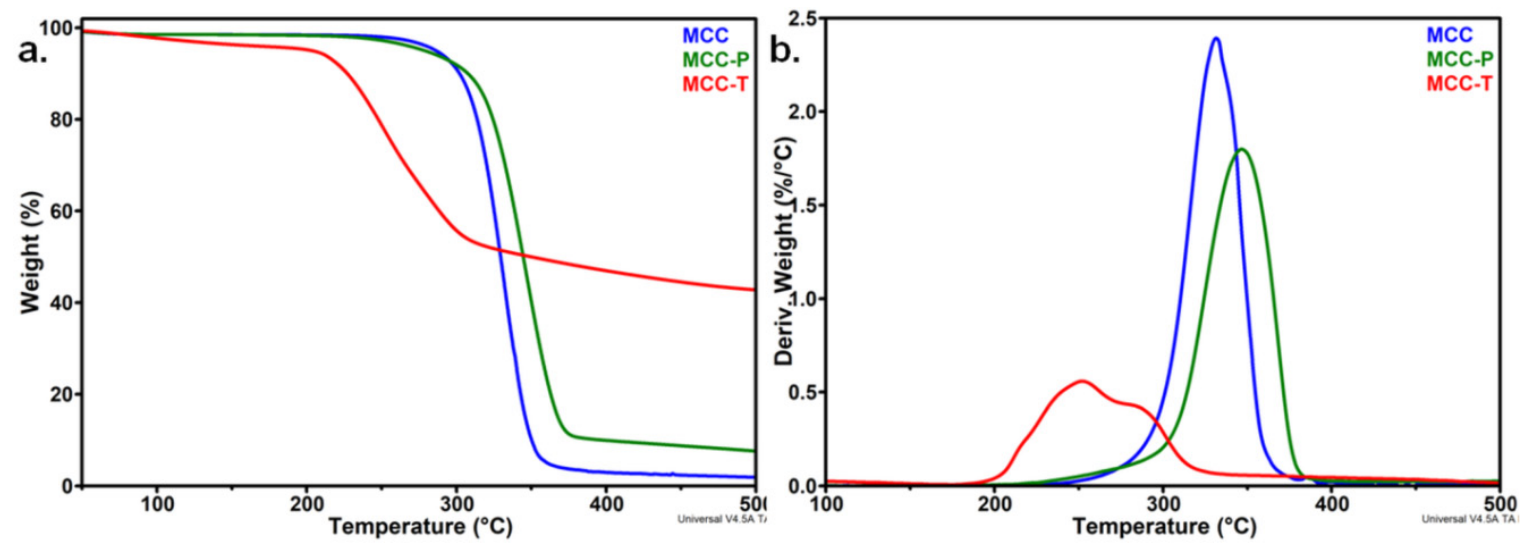

Figure 3. TGA (a) and DTG curves (b) for microcrystalline cellulose (MCC), TEMPO oxidized cellulose (MCC-T) and plasma treated cellulose (MCC-P).

The thermal stability of MCC was significantly influenced by TEMPO-mediated oxidation and only small changes were observed after the plasma treatment (Figure 3). The degradation started at a much lower temperature of $222^{\circ} \mathrm{C}$ in the case of MCC-T instead of $30{ }^{\circ} \mathrm{C}$ for pristine MCC. Similarly, the $T_{d}$ decreased by $80{ }^{\circ} \mathrm{C}$, from 331.5 to $251.9{ }^{\circ} \mathrm{C}$. These changes are due to the oxidation reactions induced by the TEMPO treatment $[27,28]$. A similar decrease of the onset degradation temperature, with about $100{ }^{\circ} \mathrm{C}$, was reported by Fukuzumi et al. in the case of TEMPO oxidized bleached kraft pulp fibers and explained by the formation of sodium carboxylate groups at the C6 primary hydroxyls on the surface of cellulose crystals and in the disordered regions [27]. Saito and Isogai reported an important decrease of the degree of polymerization (DP) in the case of TEMPO-modified cellulose cotton linter [16]. The decrease of DP, related to a lower average molecular weight and a lower thermal stability, was explained by the oxidation of all hydroxyl groups of cellulose and the formation of C6 carboxylate or aldehyde groups and C2 or C3 ketones [29]. The high broadness of the DTG peak in the case of MCC-T shows the overlap of at least two degradation processes. The first peak, at about $222{ }^{\circ} \mathrm{C}$, was determined by the degradation of more unstable anhydroglucuronate units resulting from TEMPO-oxidation, and the second at a temperature of $285^{\circ} \mathrm{C}$, lower than the $T_{d}$ of unmodified cellulose, may be ascribed to the decomposition of unmodified or slightly oxidized cellulose influenced by the adjacent sodium carboxylate groups [28].

A completely different behavior was observed after the plasma treatment of MCC (Figure 3): $T_{\text {on }}$ increased by $9{ }^{\circ} \mathrm{C}$ and $T_{d}$ by $15^{\circ} \mathrm{C}$ compared to untreated MCC. A similar increase of the maximum degradation temperature was reported for nanocellulose treated with a DBD plasma source in Ar or $\mathrm{Ar} / \mathrm{N}_{2}$ flow [20]. The better thermal stability of MCC-P compared to untreated MCC resulted from the removal of low molecular weight fractions or impurities from the MCC suspended in water under 
the influence of submerged plasma discharge [20]. The different charred residue values at $500{ }^{\circ} \mathrm{C}$ $\left(\mathrm{R}_{500}\right), 7.6 \%$ for MCC-P, $42.7 \%$ for MCC-T, and only $1.9 \%$ for MCC, also suggest different degradation processes after the treatments. Cellulose decomposed almost completely in inert atmosphere and the residue is very low for untreated MCC [29]. The large charred residue value of MCC-T, 22 times higher than that of MCC, may be related to the decomposition products of sodium anhydroglucuronate units. Furthermore, carboxylate, aldehyde, or ketone groups of MCC-T may be involved in a great number of condensation, grafting, or crosslinking reactions, resulting in an important amount of highly condensed polycyclic aromatic structures [21,30]. Moreover, the decreased DP supposed in the case of MCC-T may lead to an increased number of chain ends, which decompose at a lower temperature giving an increased amount of char [31]. Therefore, the smaller $R_{500}$ value of MCC-P compared to MCC-T, only four times higher than that of MCC, may be related to a much lower amount of oxidized cellulose after the plasma treatment. FTIR analysis may give more information on the chemical modifications induced by the treatments on the surface of cellulose.

\subsubsection{Surface Chemical Properties of Modified Celluloses}

The FTIR spectra of different treated MCC are shown in Figure 4a. FTIR spectrum of MCC shows the characteristic vibrations of cellulose: (i) $3000-3600 \mathrm{~cm}^{-1}$ due to the $\mathrm{O}-\mathrm{H}$ stretching vibrations of hydrogen bonded hydroxyl groups, (ii) $2800-3000 \mathrm{~cm}^{-1}$ due to asymmetric and symmetric stretching vibrations of $\mathrm{C}-\mathrm{H}$, (iii) at $1645 \mathrm{~cm}^{-1}$ due to the $\mathrm{O}-\mathrm{H}$ bending vibration in bound water, (iv) multiple bands between 1275 and $1435 \mathrm{~cm}^{-1}$ due to the bending and deformation vibrations of $\mathrm{C}-\mathrm{H}$ and $\mathrm{CH}_{2}$, (v) at 1162 and $897 \mathrm{~cm}^{-1}$ due to the $\mathrm{C}-\mathrm{O}-\mathrm{C}$ stretching vibrations at the $\beta$-glucosidic linkage, and (vi) at 1054 and $1030 \mathrm{~cm}^{-1}$ due to the $\mathrm{C}-\mathrm{O}$ stretching vibrations $[26,32,33]$.
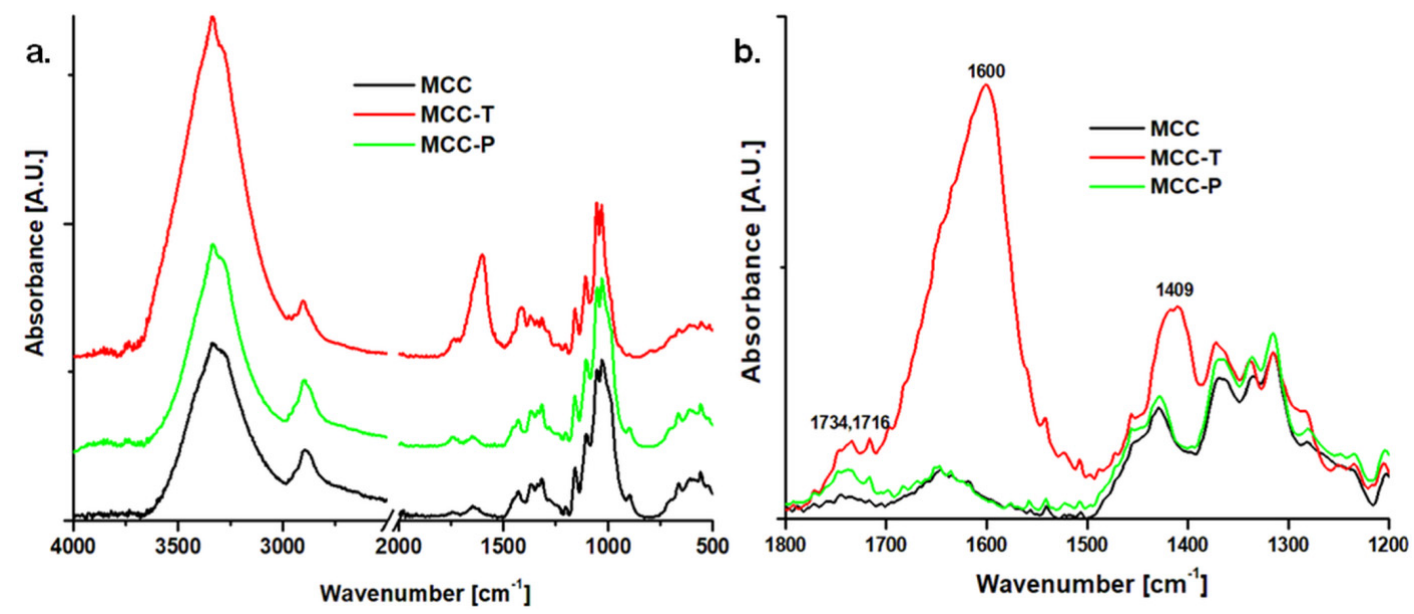

Figure 4. FTIR spectra of MCC, MCC-T and MCC-P (a); FTIR spectra in the range from1800 to $1200 \mathrm{~cm}^{-1}(\mathbf{b})$.

Major changes were noticed in the FTIR spectrum of MCC-T (Figure 4). A new and intense peak appeared at $1600 \mathrm{~cm}^{-1}$ which is characteristic of asymmetric $\mathrm{C}=\mathrm{O}$ stretching vibrations in $\mathrm{COO}^{-}$of sodium carboxylate [34,35]. A new and broad band appeared at $1409 \mathrm{~cm}^{-1}$ due to the symmetric stretching vibrations of $\mathrm{COO}^{-1}$ [34]. In addition, two new bands were noticed in MCC-T at 1716 and $1734 \mathrm{~cm}^{-1}$ (Figure $4 \mathrm{~b}$ ), which may be associated to the $\mathrm{C}=\mathrm{O}$ stretching vibrations in carboxylic acid $[27,36,37]$.

Small changes were observed between the FTIR spectra of MCC-P and untreated MCC (Figure 4a,b). A broad band at $1737 \mathrm{~cm}^{-1}$ and a second band at $1716 \mathrm{~cm}^{-1}$ were noticed in MCC-P similar to MCC-T, and they are assigned to the $\mathrm{C}=\mathrm{O}$ stretching vibrations in carboxylic acid. The appearance of the new bands around $1734 / 1737 \mathrm{~cm}^{-1}$ indicates the oxidation of MCC by both TEMPO and plasma treatments [36]. The degree of oxidation (DO) may be estimated from the FTIR spectra by comparing 
the intensity of the band near $1735 \mathrm{~cm}^{-1}$ with that of the band at $1050 \mathrm{~cm}^{-1}$ which comes from the cellulose backbone [36]. Different DO values were obtained for MCC-T and MCC-P, $0.06 \%$ and $0.12 \%$. They correlate with the different oxidation intensity induced by the treatments. Similar DO values were reported for TEMPO-mediated oxidation of cellulose whiskers and cellulose from pulp residue in comparable reaction conditions $[34,36]$.

For a better understanding of the chemical changes on the surface of MCC after the treatments, untreated and treated cellulose was also characterized by XPS. Survey spectra are shown in Figure 5 . XPS survey scans indicate the presence of carbon at $286.3 \mathrm{eV}$ and oxygen at $533.3 \mathrm{eV}$ in all samples and, in addition, chlorine (199.3 eV) and sodium (1072.3 eV) [38] in MCC-T. The O KLL Auger peak was also noticed in all survey spectra at $978 \mathrm{eV}$. The $\mathrm{O} / \mathrm{C}$ ratio differed slightly before and after treatments (Table 1) and it was close to the theoretical ratio for pure cellulose (0.83). It can be supposed that $\mathrm{NaCl}$ is present as an impurity from the TEMPO treatment, however the exceeding Na could come from sodium carboxylate, also highlighted by FTIR.

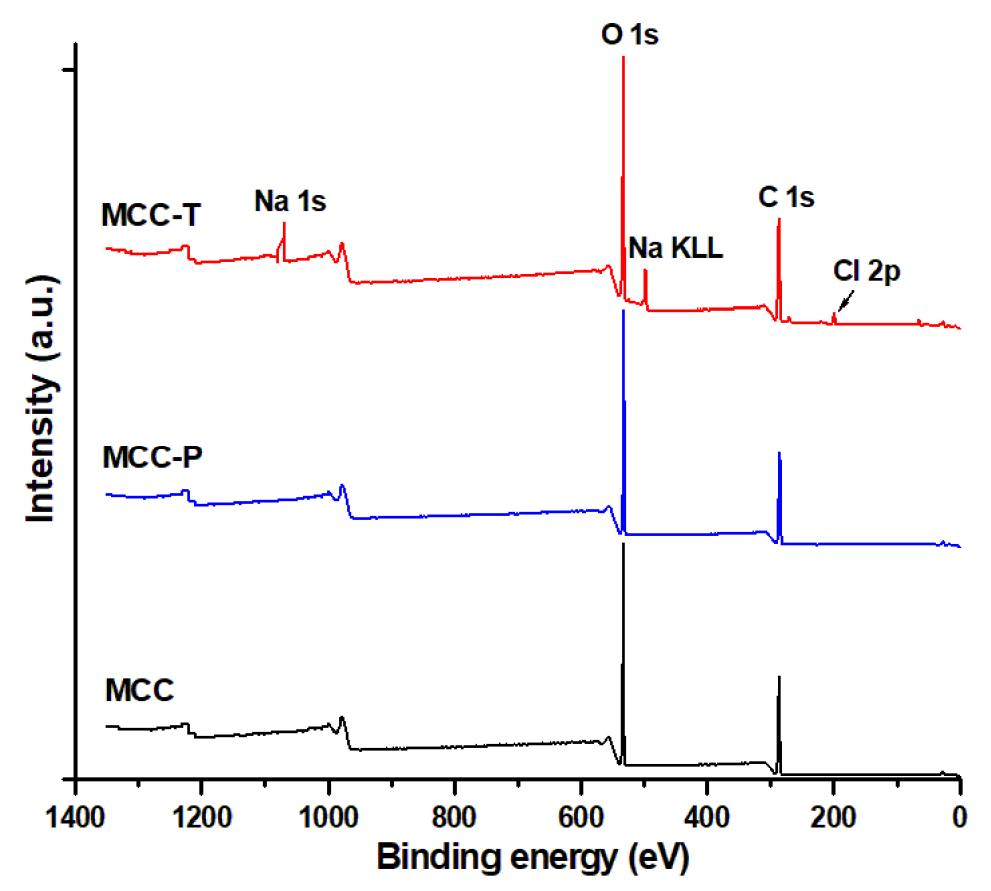

Figure 5. XPS survey spectra of different treated MCC.

Table 1. The elemental surface composition, in atomic \%, from XPS survey spectra before (MCC) and after the treatments (MCC-T and MCC-P).

\begin{tabular}{cccccc}
\hline Samples & C1s (\%) & O1s (\%) & Na1s (\%) & Cl 2p (\%) & O/C \\
\hline MCC & 57.3 & 42.7 & - & - & 0.75 \\
MCC-T & 52.8 & 39.4 & 5.3 & 2.5 & 0.75 \\
MCC-P & 56.9 & 43.1 & - & - & 0.76 \\
\hline
\end{tabular}

High resolution XPS spectra for C1s and O1s regions are shown in Figure 6. The C1s peak was fitted with 3 components in the case of MCC and 4 components for treated cellulose (Table 2): $\mathrm{C}_{1}$ corresponding to $\mathrm{C}-\mathrm{C}$ or $\mathrm{C}-\mathrm{H}$ at a binding energy of $284.6 \mathrm{eV}, \mathrm{C}_{2}$ assigned to a carbon bonded to a single oxygen in alcohol or ether groups $(\mathrm{C}-\mathrm{O})$ at a binding energy of $286.3 \mathrm{eV}, \mathrm{C}_{3}$ ascribed to $\mathrm{O}-\mathrm{C}-\mathrm{O}$ or $\mathrm{C}=\mathrm{O}$ at $288.0 \mathrm{eV}$, and $\mathrm{C}_{4}$ in $\mathrm{O}-\mathrm{C}=\mathrm{O}$ at $289.7 \mathrm{eV}[39,40]$. The $\mathrm{C} 3 / \mathrm{C} 2$ ratio, $0.29,0.41$ and 0.31 for MCC, MCC-T and MCC-P, is higher than the theoretical value (0.2), showing the presence of carbonyl groups and a higher degree of oxidation, especially for MCC-T. In contrast to MCC, both treated celluloses contain $\mathrm{C}_{4}$ species (i.e., carboxyl or carboxylate groups) but MCC-T in a higher proportion. In general, 
the TEMPO treatment of cellulose led to a much higher degree of oxidation than the plasma one, which is obvious from the higher increase of $C_{3}$ and $C_{4}$ proportion at the expense of $C_{2}$ in this case. Similar trends were reported by Coseri et al. for differently oxidized microcrystalline cellulose [38].
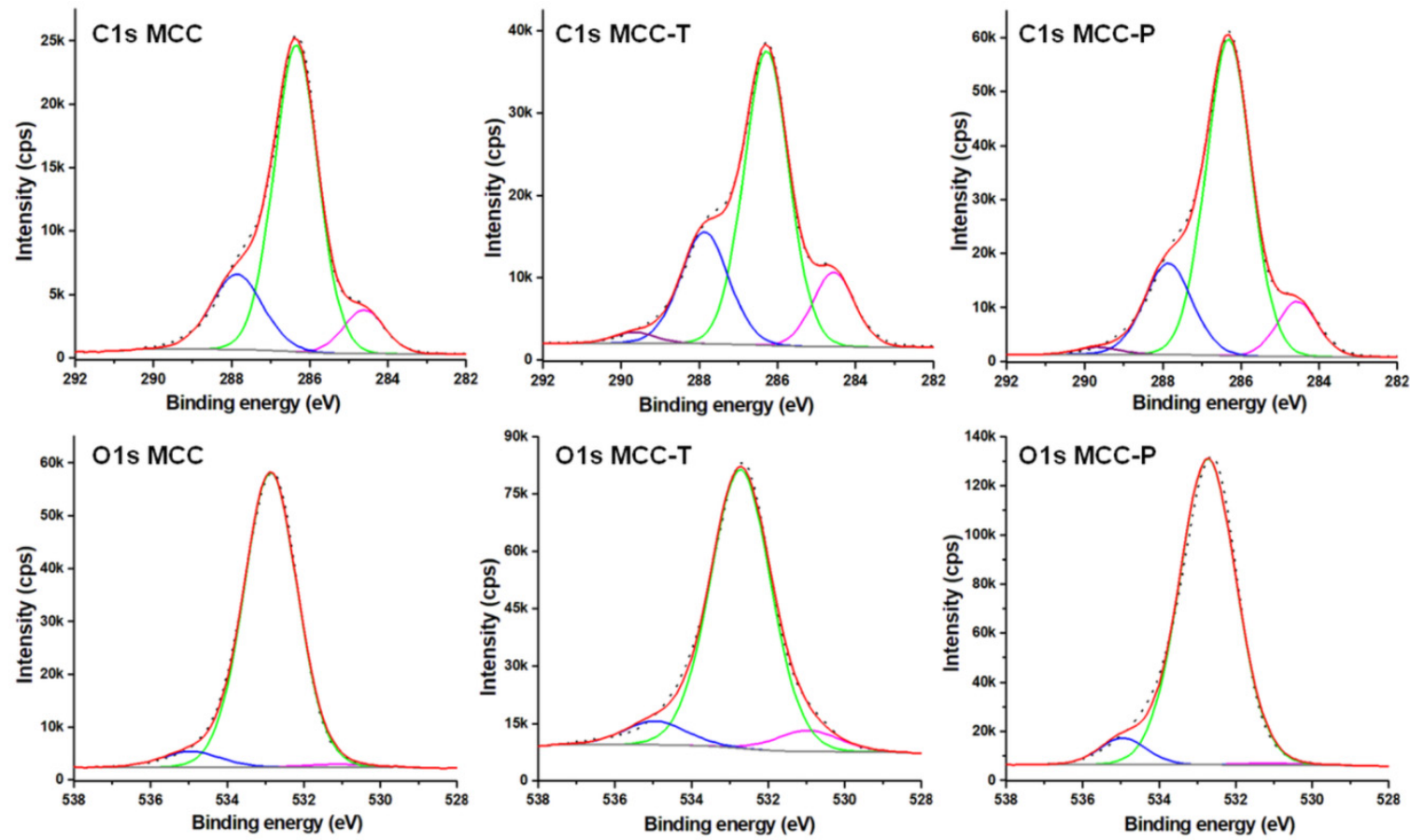

Figure 6. High resolution XPS spectra and deconvolution in the C1s and O1s regions.

Table 2. The relative atomic concentrations of differently bound carbon and oxygen atoms as determined from high resolution XPS spectra.

\begin{tabular}{cccccccc}
\hline \multirow{2}{*}{ Samples } & \multicolumn{9}{c}{$\mathrm{C} 1 \mathbf{s}$} & \multicolumn{3}{c}{ O1s } \\
\cline { 2 - 8 } & $\mathbf{C}_{\mathbf{1}} \mathbf{( \% )}$ & $\mathbf{C}_{\mathbf{2}} \mathbf{( \% )}$ & $\mathbf{C}_{\mathbf{3}} \mathbf{( \% )}$ & $\mathbf{C}_{\mathbf{4}} \mathbf{( \% )}$ & $\mathbf{O}_{\mathbf{1}} \mathbf{( \% )}$ & $\mathbf{O}_{\mathbf{2}} \mathbf{( \% )}$ & $\mathbf{O}_{\mathbf{3}} \mathbf{( \% )}$ \\
\hline MCC & 9.4 & 70.3 & 20.3 & - & 1.1 & 93.4 & 5.5 \\
MCC-T & 14.0 & 59.6 & 24.3 & 2.1 & 6.7 & 85.7 & 7.6 \\
MCC-P & 10.5 & 67.4 & 20.6 & 1.4 & 0.6 & 92.7 & 6.8 \\
\hline
\end{tabular}

Some more information can be obtained from the deconvolution of O1s in high resolution XPS spectra (Figure 6). To O1s region contributed: $\mathrm{O}_{1}$, double bonded $\mathrm{O}(\mathrm{C}=\mathrm{O})$ in sodium carboxylate and other oxidized groups (aldehydes, ketones) at $531.0 \mathrm{eV}, \mathrm{O}_{2}$, single bonded $\mathrm{O}$ from $\mathrm{C}-\mathrm{OH}$ and $\mathrm{C}-\mathrm{O}-\mathrm{C}$ of pyranose ring at $532.9 \mathrm{eV}$ and $\mathrm{O}_{3}$, which can be assigned to carboxylic acid functional groups and water,

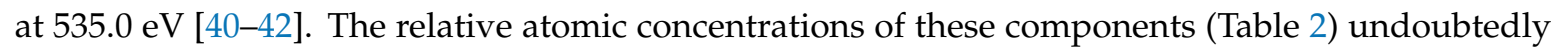
show that the plasma treatment induced a small increase of carboxylic groups on cellulose, ensuring a slight oxidation while the TEMPO treatment determined a significant oxidation of cellulose, especially as carboxylate and carboxylic groups. The cellulose surface changes observed by XPS are in good agreement and strengthen the results obtained by FTIR.

\subsection{Thermal Properties of PHB Composites with Different Treated MCC}

Untreated and surface treated celluloses were used as reinforcement in PHB. Figure 7 shows the TGA and derivative (DTG) curves of PHB composites containing $2 \mathrm{wt} \% \mathrm{MCC}$, MCC-T, and MCC-P. Although the effect of different treated MCC on the thermal stability of PHB is similar to the effect of the treatments on cellulose (Figure 3), meaning an increased stability for MCC-P and a decreased one for 
MCC-T, the difference between the characteristic temperatures of the composites is much attenuated (Table 3).

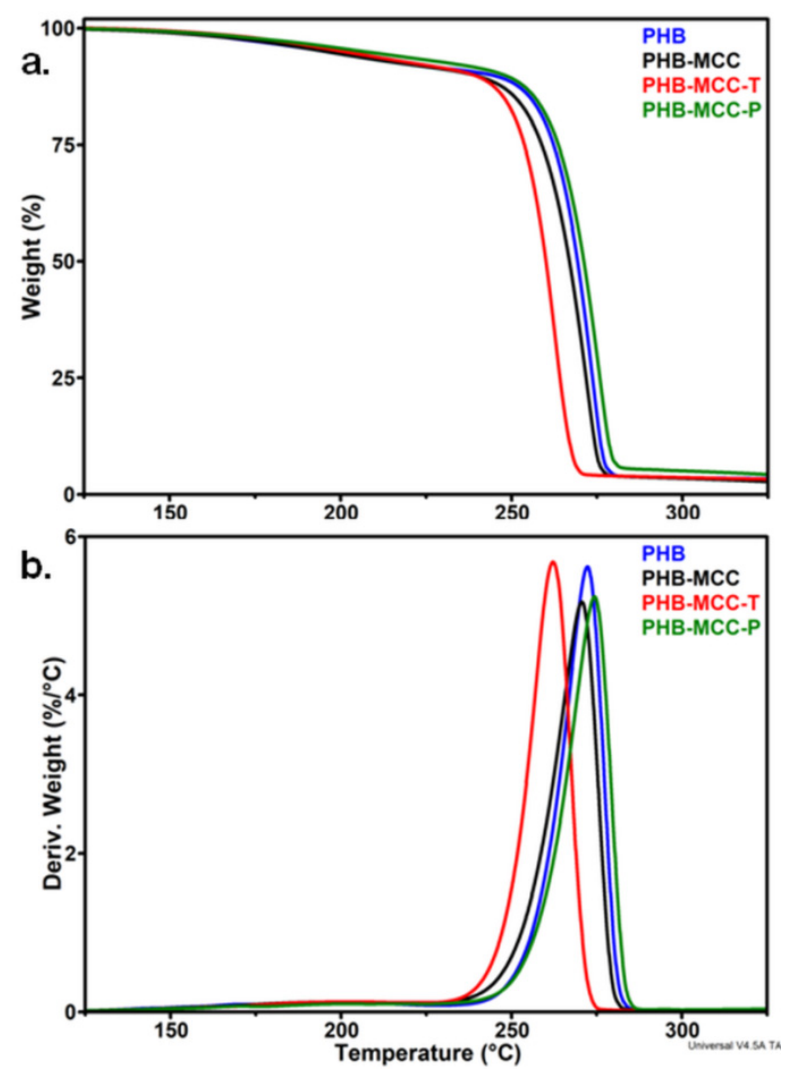

Figure 7. TGA (a) and DTG (b) curves of PHB composites with untreated and treated MCC.

Table 3. TGA results for PHB composites with different treated MCC.

\begin{tabular}{ccccc}
\hline Characteristic Temperatures & PHB & PHB-MCC & PHB-MCC-T & PHB-MCC-P \\
\hline$T_{5 \%},{ }^{\circ} \mathrm{C}$ & 195.6 & 195.7 & 200.9 & 206.8 \\
$T_{\mathrm{on}},{ }^{\circ} \mathrm{C}$ & 262.6 & 259.4 & 253.7 & 263.6 \\
$T_{\mathrm{d}},{ }^{\circ} \mathrm{C}$ & 272.3 & 270.6 & 262.1 & 274.3 \\
\hline
\end{tabular}

The addition of MCC in PHB decreases the $T_{\text {on }}$ and $T_{d}$, with only $2-3{ }^{\circ} \mathrm{C}$, which is a common effect of cellulose fillers in PHB [7]. One cause of the increased degradation was supposed to be the higher thermal conductivity of cellulose compared to PHB [12]. Impurities, such as increased melt viscosity after the incorporation of cellulose in the polymer matrix or the presence of bond water in cellulose, were also considered as sources of an enhanced thermal degradation of PHB after the addition of cellulose [7].

The addition of MCC-T decreased the $T_{\text {on }}$ and $T_{d}$ of $\mathrm{PHB}$ composites with $9-10^{\circ} \mathrm{C}$. The presence of oxidized groups on the surface of MCC-T may enhance not only the thermal degradation of cellulose but also the degradation of PHB because they may catalyze the depolymerization reaction of PHB by interacting with the carboxyl group and favoring the chain scission reaction [43]. Considering that the melt processing took place at about $170^{\circ} \mathrm{C}$, the effect of oxidized compounds might be much enhanced at this temperature. Moreover, XPS survey spectra (Figure 5) and FTIR showed the presence of Na as sodium carboxylate on the surface of MCC-T which may catalyze the depolymerization reaction of PHB. Indeed, previous study has shown that many metal compounds but especially $\mathrm{Na}$ and $\mathrm{Mg}$ accelerate the random chain scission and the degradation of PHB [44]. 
In contrast to MCC and MCC-T, the addition of MCC-P slightly increased the $T_{o n}$ and $T_{d}$ of PHB composites with $1-2{ }^{\circ} \mathrm{C}$. Plasma treated MCC led to a better thermal behavior of PHB-MCC-P composite because of the mild oxidation of cellulose following the plasma treatment in contrast to the harsh TEMPO oxidation, also illustrated by the FTIR results. Moreover, the cleaning of cellulose during the submerged plasma treatment removes metals or other impurities which may catalyze the decomposition of PHB at high temperature [44]. It is remarkable that the thermal stability of composites at processing temperature, illustrated by the temperature at $5 \%$ weight loss $\left(T_{5 \%}\right)$, was much improved in PHB composites containing treated MCC (Table 3). An increase of $T_{5 \%}$ with about $11^{\circ} \mathrm{C}$ in the case of PHB-MCC-P and $5{ }^{\circ} \mathrm{C}$ in the case of PHB-MCC-T was noticed.

The DSC thermograms during the cooling and second heating cycles are shown in Figure 8 and the corresponding thermal parameters are listed in Table 4. Important differences between the crystallization behaviors of composites with different treated MCC were noticed in the cooling cycle (Figure 8a).
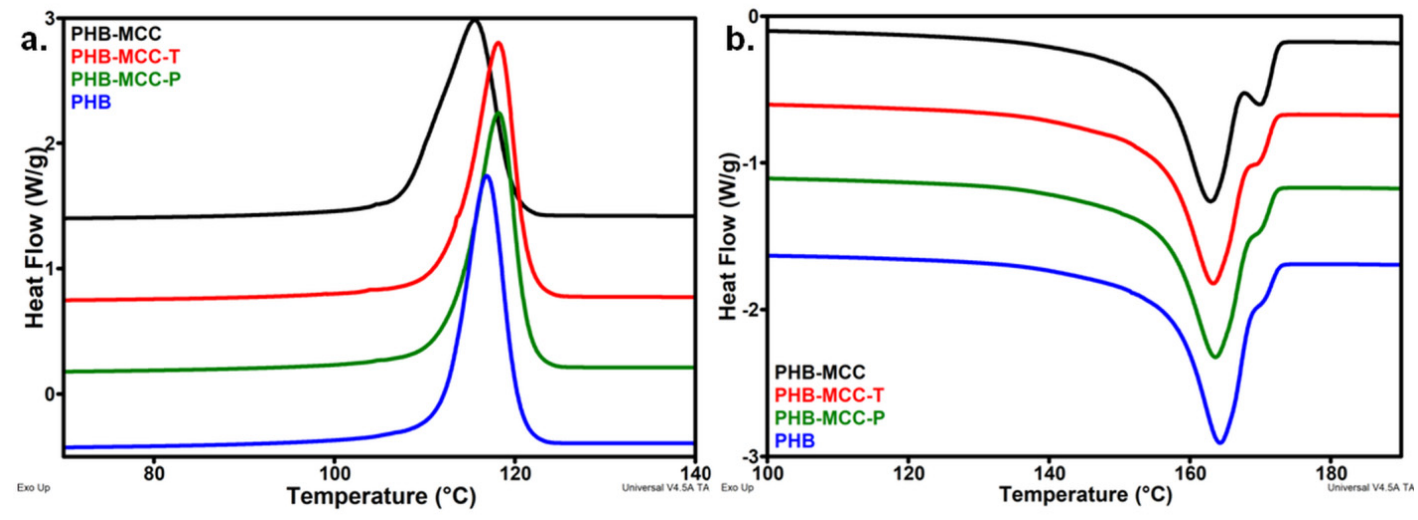

Figure 8. DSC thermograms of PHB and composites for the first (a) and second heating (b).

Table 4. DSC data collected from the heating-cooling-heating DSC curves of composites.

\begin{tabular}{ccccc}
\hline Composites & PHB & PHB-MCC & PHB-MCC-T & PHB-MCC-P \\
\hline$T_{\mathrm{c}},{ }^{\circ} \mathrm{C}$ & 116.9 & 115.5 & 118.2 & 118.2 \\
$\Delta H_{\mathrm{C}}$ & 76.6 & 74.0 & 77.1 & 76.9 \\
$T_{\mathrm{m}},{ }^{\circ} \mathrm{C}$ & 164.2 & 163.0 & 163.3 & 163.6 \\
$\Delta H_{\mathrm{m}}$ & 81.1 & 78.4 & 81.5 & 81.5 \\
$X_{\mathrm{c}}, \%$ & 55.5 & 54.8 & 57.0 & 57.0 \\
\hline
\end{tabular}

$\Delta H_{\mathrm{c}}, T_{\mathrm{c}}$-crystallization enthalpy and crystallization temperature. $\Delta H_{\mathrm{m}}, T_{\mathrm{m}}$-melting enthalpy and melting temperature.

As observed in Figure 8a, The $T_{c}$ of PHB slightly increased in the composites with treated MCC and decreased in the composite with untreated cellulose. Although the difference between the composites with untreated and treated cellulose is at most $3{ }^{\circ} \mathrm{C}$, this reflects the influence of MCC treatment on the crystallization of PHB. Moreover, the width at half-height of crystallization peak was almost double in the case of PHB-MCC compared to PHB and the composites with treated MCC. The broader crystallization peak and the lower $T_{c}$ show that MCC hindered the crystallization of PHB and slowed down the crystallization rate. Previous study has shown that nanocellulose is a good nucleating agent in PHB, increasing the crystallization rate [7]. Therefore, the effect of MCC on the crystallization of PHB may be due to the poor interface with the polymer and the micrometric size of cellulose fibers. On the contrary, the good influence of treated fibers suggests a better interface between PHB and MCC-T or MCC-P. In addition, both plasma and TEMPO treatments contributed to the defibrillation of cellulose, reducing the size of the fibers, as pointed out by previous studies [16,21].

Similar behavior was observed in the second heating cycle, with a main melting peak and a shoulder at a higher temperature (Figure $8 b$ ). The melting temperature remained unchanged after the 
addition of cellulose, regardless the treatment. However, the crystallinity followed the same trend as observed in the cooling cycle, a slight decrease in the composite with untreated MCC and a slight increase in that containing treated celluloses. This may be an effect of a better dispersion of treated MCC in PHB and better interactions between PHB and plasma or TEMPO treated cellulose. SEM analysis may enlighten this aspect.

\subsection{SEM Images of PHB Composites with Treated MCC}

The SEM images in Figure 9 show the surface morphology of the fractured PHB composites with different treated cellulose.
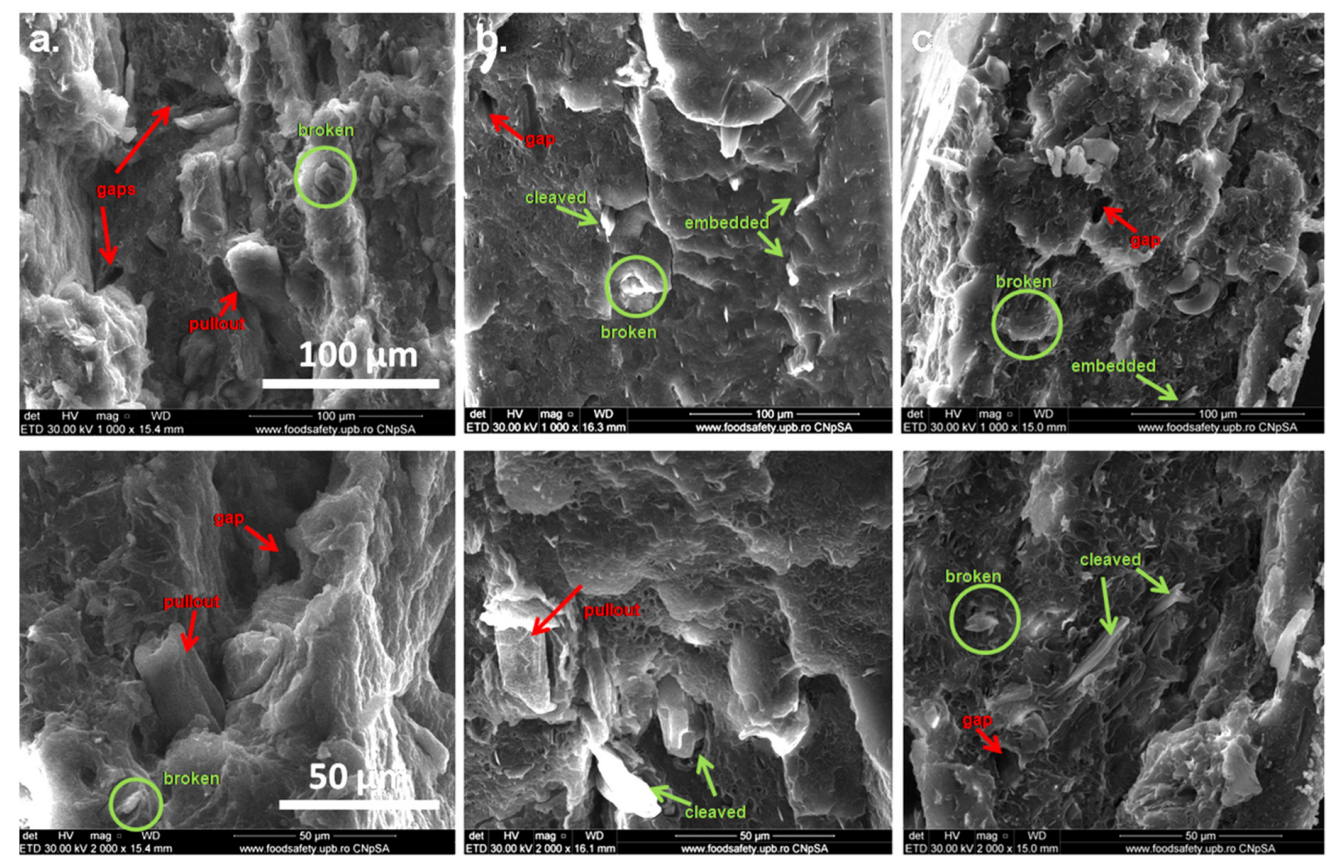

Figure 9. SEM images of PHB composites with different treated MCC: untreated MCC $((\mathbf{a}) ; \times 1000$, $\times 2000)$; MCC-T $((\mathbf{b}) ; \times 1000, \times 2000) ;$ MCC-P $((\mathbf{c}) ; \times 1000, \times 2000)$.

Both well embedded broken fibers and pullout fibers and gaps were observed in all the samples but the frequency of debonded fibers and gaps was higher in PHB-MCC than in the composites with treated fibers. Notably, the presence of fibers broken on the transverse section indicates a good PHB-cellulose interface, and such fibers were frequently observed in the composites with TEMPO and plasma modified fibers. This shows good bonding between the polymer and cellulose fibers, which may be benefic to their mechanical properties. Similarly, thinner submicron fibers were mostly observed in the composites with MCC-T and MCC-P, because both TEMPO oxidation and plasma treatment decrease the size of original cellulose fibers and caused defibrillation [13,21]. A better dispersion of fibers was noticed in the case of PHB-MCC-P.

\subsection{DMA Analysis of PHB Composites with Treated MCC}

The stiffness of PHB composites as function of temperature was investigated by DMA (Figure 10). The addition of untreated and treated MCC in PHB led to an increase of the storage modulus $\left(E^{\prime}\right)$ (Figure 10a). However, the increase was more accentuate (2-3 times) for the composites with treated MCC, especially with plasma treated fibers. An increase of the $E^{\prime}$ by $184 \%$ for PHB-MCC-P and $167 \%$ for PHB-MCC-T was noticed at room temperature (Table 5). 

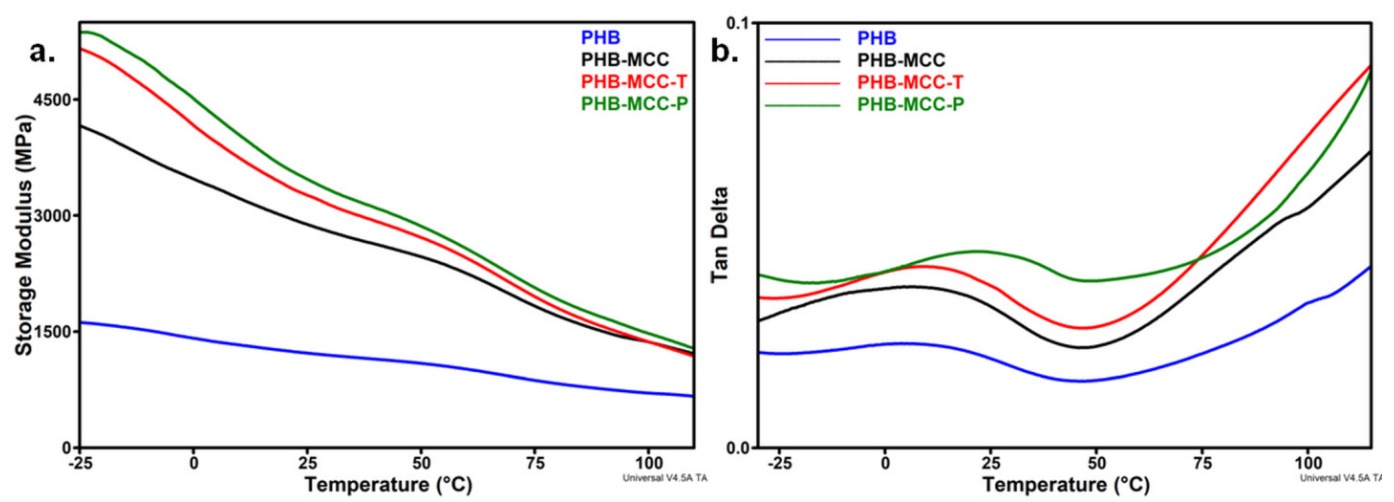

Figure 10. Storage modulus (a) and $\tan \delta(\mathbf{b})$ vs temperature curves for PHB and composites with different treated MCC.

Table 5. DMA data for PHB and composites: PHB-MCC, PHB-MCC-T and PHB-MCC-P.

\begin{tabular}{ccccc}
\hline Composites & PHB & PHB-MCC & PHB-MCC-T & PHB-MCC-P \\
\hline$T_{g},{ }^{\circ} \mathrm{C}$ & 3.8 & 5.8 & 9.2 & 21.8 \\
$E^{\prime}\left(-25^{\circ} \mathrm{C}\right), \mathrm{MPa}$ & 1617 & 4164 & 5160 & 5370 \\
$E^{\prime}\left(25^{\circ} \mathrm{C}\right), \mathrm{MPa}$ & 1221 & 2885 & 3264 & 3470 \\
$E^{\prime}\left(75^{\circ} \mathrm{C}\right), \mathrm{MPa}$ & 871 & 1830 & 1952 & 2068 \\
\hline
\end{tabular}

The more accentuated decrease of the $E^{\prime}$, observed between about $-10{ }^{\circ} \mathrm{C}$ and $25-30{ }^{\circ} \mathrm{C}$, was determined by the transition of PHB from glassy to rubbery state and the activation of molecular segmental motions at the glass transition temperature [44]. Variation of loss factor $(\tan \delta)$ with temperature (Figure 10b) emphasizes the relative contributions of the elastic and viscous components when temperature increases. A shift of the glass transition temperature $\left(T_{g}\right)$ to a higher temperature was observed for all the composites compared to $\mathrm{PHB}$, however the highest shift, of $18{ }^{\circ} \mathrm{C}$, was observed for PHB-MCC-P. This shows a good interface and a uniform dispersion of MCC-P in the polymer matrix. Plasma treatment induced a mild oxidation on the surface of cellulose, as indicated by both FTIR and XPS results, and the formation of carboxylate groups may increase the compatibility between poly(hydroxyl butyric acid) matrix and $\mathrm{COOH}$ bearing cellulose. The influence of MCC-T was not so important, probably because of the opposite effects of surface functionalization and degradation. TEMPO oxidation induces the surface functionalization of cellulose, improving the interface and mechanical properties, but the presence of metal compounds and other impurities from the chemical treatment enhances the decomposition of PHB, thus decreasing the molecular weight and the mechanical properties $[7,45]$. This is supported by the lower thermal stability of this composite (Figure 7). As a result, the increase of the mechanical properties in PHB-MCC-T was not as high as in the case of PHB-MCC-P, although TEMPO oxidation induced a much strong surface modification of cellulose.

\section{Conclusions}

Microcrystalline cellulose was surface modified by a plasma treatment in liquid using a Y-shaped tube and TEMPO mediated oxidation. The plasma treatment of water suspensions of cellulose ensured an increased flow of the oxidative gas, being a simple and highly reproducible method for cellulose modification. FTIR and XPS results showed that both treatments led to the surface functionalization of cellulose. However, TEMPO oxidation had a much stronger effect, leading to a decrease of thermal stability of MCC by $80^{\circ} \mathrm{C}$. Plasma and TEMPO modified celluloses were incorporated in a PHB matrix and they influenced the morphology and thermal and mechanical properties of composites. Both treatments improved the fiber-polymer interface and the mechanical properties of PHB composites. An increase of the storage modulus by $184 \%$ in PHB-MCC-P and 167\% in PHB-MCC-T was noticed at 
room temperature. The increase of the mechanical properties in the composite with TEMPO oxidized cellulose was not as high as in the case of that containing plasma treated cellulose, although the chemical treatment induced a much stronger surface modification of cellulose. The main cause of this behavior is, probably, the significant degradation of MCC following TEMPO oxidation. The PHB composites containing plasma modified cellulose are promising materials for biomedical applications. In addition, the filamentary Y-shaped DBD plasma jet immersed in the liquid suspension of cellulose is an environmentally friendly, simple, and cheap treatment, which is proposed as an alternative to the mechano-chemical methods usually employed for the modification of cellulose.

Author Contributions: Conceptualization, D.M.P. and G.D.; methodology, D.M.P. (cellulose treatments and composites), S.V. (plasma experiments), and C.-A.N. (thermal experiments); formal analysis and investigation, S.V. and L.G.C. (plasma), S.A.S. (TEMPO, composites), C.-A.N. (TGA, DSC composites), A.R.G. (DMA), C.M.D. (TGA celluloses), and R.T. (SEM); writing—original draft preparation, D.M.P. and S.V.; writing—review \& editing, D.M.P.; validation, G.D.; supervision, D.M.P. All authors have read and agreed to the published version of the manuscript.

Funding: This work was funded by two grants of the Romanian Ministry of Research and Innovation, CCCDI-UEFISCDI, project number PN-III-P1-1.2-PCCDI-2017-0428 Napoli19 (PCCDI 40/2018) and project number PN-III-P1-1.2-PCCDI-2017-0637 MultiMonD2 (PCCDI 33/2018) within PNCDI III.

Acknowledgments: The authors gratefully acknowledge Veronica Satulu for XPS measurements.

Conflicts of Interest: The authors declare no conflict of interest.

\section{References}

1. Gandini, A.; Belgacem, M.N. The state of the art of polymers from renewable resources. In Handbook of Biopolymers and Biodegradable Plastics: Properties, Processing and Applications, 1st ed.; Ebnesajjad, S., Ed.; Elsevier Inc.: Kidlington, Oxford, UK, 2013; Chapter 4; pp. 71-85.

2. Kargarzadeh, H.; Huang, J.; Lin, N.; Ahmad, I.; Marino, M.; Dufresne, A.; Thomas, S.; Gałęski, A. Recent developments in nanocellulose-based biodegradable polymers, thermoplastic polymers, and porous nanocomposites. Prog. Polym. Sci. 2018, 87, 197-227. [CrossRef]

3. Wróblewska-Krepsztul, J.; Rydzkowski, T.; Michalska-Pożoga, I.; Thakur, V.K. Biopolymers for Biomedical and Pharmaceutical Applications: Recent Advances and Overview of Alginate Electrospinning. Nanomaterials (Basel) 2019, 9, 404.

4. Albuquerque, P.B.S.; Malafaia, C.B. Perspectives on the production, structural characteristics and potential applications of bioplastics derived from polyhydroxyalkanoates. Int. J. Biol. Macromol. 2018, 107, 615-625. [CrossRef]

5. Panaitescu, D.M.; Nicolae, C.A.; Gabor, A.R.; Trusca, R. Thermal and mechanical properties of poly(3-hydroxybutyrate) reinforced with cellulose fibers from wood waste. Ind. Crops Prod. 2020, 145, 112071. [CrossRef]

6. Wang, L.; Zhu, W.; Wang, X.; Chen, X.; Chen, G.-Q.; Xu, K. Processability modifications of poly(3-hydroxybutyrate) by plasticizing, blending, and stabilizing. J. Appl. Polym. Sci. 2008, 107, 166-173. [CrossRef]

7. Srithep, Y.; Ellingham, T.; Peng, J.; Sabo, R.; Clemons, C.; Turng, L.-S.; Pilla, S. Melt compounding of poly (3-hydroxybutyrate-co-3-hydroxyvalerate)/nanofibrillated cellulose nanocomposites. Polym. Degrad. Stab. 2013, 98, 1439-1449. [CrossRef]

8. Panaitescu, D.M.; Nicolae, C.A.; Frone, A.N.; Chiulan, I.; Stanescu, P.O.; Draghici, C.; Iorga, M.; Mihailescu, M. Plasticized poly(3-hydroxybutyrate) with improved melt processing and balanced properties. J. Appl. Polym. Sci. 2017, 134, 44810. [CrossRef]

9. Frone, A.N.; Panaitescu, D.M.; Chiulan, I.; Nicolae, C.A.; Vuluga, Z.; Vitelaru, C.; Damian, M.C. The effect of cellulose nanofibers on the crystallinity and nanostructure of poly (lactic acid) composites. J. Mater. Sci. 2016, 51, 9771-9791. [CrossRef]

10. Garcia-Garcia, D.; Lopez-Martinez, J.; Balart, R.; Strömberg, E.; Moriana, R. Reinforcing capability of cellulose nanocrystals obtained from pine cones in a biodegradable poly(3-hydroxybutyrate)/poly( $\varepsilon$-caprolactone) (PHB/PCL) thermoplastic blend. Eur. Polym. J. 2018, 104, 10-18. [CrossRef] 
11. Panaitescu, D.M.; Frone, A.N.; Chiulan, I.; Gabor, R.A.; Spataru, I.C.; Căşărică, A. Biocomposites from polylactic acid and bacterial cellulose nanofibers obtained by mechanical treatment. BioResources 2017, 12, 662-672. [CrossRef]

12. Ambrosio-Martin, J.; Fabra, M.J.; Lopez-Rubio, A.; Gorrasi, G.; Sorrentino, A.; Lagaron, J.M. Assessment of ball milling as a compounding technique to develop nanocomposites of poly(3-hydroxybutyrate-co-3hydroxyvalerate) and bacterial cellulose nanowhiskers. J. Polym. Environ. 2016, 24, 241-254. [CrossRef]

13. Nechyporchuk, O.; Belgacem, M.N.; Bras, J. Production of cellulose nanofibrils: A review of recent advances. Ind. Crops Prod. 2016, 93, 2-25. [CrossRef]

14. Agarwal, C.; Csoka, L. Surface-Modified Cellulose in Biomedical Engineering In Materials for Biomedical Engineering: Bioactive Materials, Properties, and Applications; Grumezescu, V., Grumezescu, A.M., Eds.; Elsevier Radarweg: Amsterdam, The Netherlands, 2019; Chapter 6; pp. 251-261.

15. Frone, A.N.; Chiulan, I.; Panaitescu, D.M.; Cristian, A.N.; Ghiurea, M.; Galan, A.-M. Isolation of cellulose nanocrystals from plum seed shells, structural and morphological characterization. Mater. Lett. 2017, 194, 160-163. [CrossRef]

16. Saito, T.; Isogai, A. TEMPO-mediated oxidation of native cellulose. The effect of oxidation conditions on chemical and crystal structures of the water-insoluble fractions. Biomacromolecules 2004, 5, 1983-1989. [CrossRef]

17. Besbes, I.; Alila, S.; Boufi, S. Nanofibrillated cellulose from TEMPO-oxidized eucalyptus fibres: Effect of the carboxyl content. Carbohydr. Polym. 2011, 84, 975-983. [CrossRef]

18. Lavoine, N.; Desloges, I.; Dufresne, A.; Bras, J. Microfibrillated cellulose-Its barrier properties and applications in cellulosic materials: A review. Carbohydr. Polym. 2012, 90, 735-764. [CrossRef]

19. Missoum, K.; Belgacem, M.N.; Bras, J. Nanofibrillated Cellulose Surface Modification: A Review. Materials (Basel) 2013, 6, 1745-1766. [CrossRef]

20. Panaitescu, D.M.; Vizireanu, S.; Nicolae, C.A.; Frone, A.N.; Casarica, A.; Carpen, L.G.; Dinescu, G. Treatment of nanocellulose by submerged liquid plasma for surface functionalization. Nanomaterials (Basel) 2018, 8, 467. [CrossRef]

21. Vizireanu, S.; Panaitescu, D.M.; Nicolae, C.A.; Frone, A.N.; Chiulan, I.; Ionita, M.D.; Satulu, V.; Carpen, L.G.; Petrescu, S.; Birjega, R.; et al. Cellulose defibrillation and functionalization by plasma in liquid treatment. Sci. Rep. 2018, 8, 15473. [CrossRef]

22. International Organisation for Standardization (ISO). ISO 527-2:2012: Plastics—Determination of Tensile Properties-Part. 2: Test. Conditions for Moulding and Extrusion Plastics; International Organization for Standardization: Geneva, Switzeland, 2012.

23. Teodorescu, M.; Bazavan, M.; Ionita, E.R.; Dinescu, G. Characteristics of a long and stable filamentary argon plasma jet generated in ambient atmosphere. Plasma Sources Sci. Technol. 2015, 24, 25033. [CrossRef]

24. Carpen, L.G.; Chireceanu, C.; Teodorescu, M.; Chiriloaie, A.; Teodoru, A.; Dinescu, G. The effect of argon/oxygen and argon/nitrogen atmospheric plasma jet on stored products pests. Rom. J. Phys. 2019, 64, 503.

25. Barham, P.J.; Keller, A.; Otun, E.L.; Holmer, P.A. Crystallization and morphology of a bacterial thermoplastic: Poly-3-hydroxybutyrate. J. Mater. Sci. 1984, 19, 2781-2794. [CrossRef]

26. Baruah, J.; Deka, R.C.; Kalita, E. Greener production of microcrystalline cellulose (MCC) from Saccharum spontaneum (Kans grass): Statistical optimization. Int. J. Biol. Macromol. 2020, 154, 672-682. [CrossRef] [PubMed]

27. Fukuzumi, H.; Saito, T.; Iwata, T.; Kumamoto, Y.; Isogai, A. Transparent and high gas barrier films of cellulose nanofibers prepared by TEMPO-mediated oxidation. Biomacromolecules 2009, 10, 162-165. [CrossRef] [PubMed]

28. Fukuzumi, H.; Saito, T.; Okita, Y.; Isogai, A. Thermal stabilization of TEMPO-oxidized cellulose. Polym. Degrad. Stab. 2010, 95, 1502-1508. [CrossRef]

29. Loof, D.; Hiller, M.; Oschkinat, H.; Koschek, K. Quantitative and qualitative analysis of surface modified cellulose utilizing TGA-MS. Materials (Basel) 2016, 9, 415. [CrossRef]

30. Peng, Y.; Gardner, D.J.; Han, Y.; Kiziltas, A.; Cai, Z.; Tshabalala, M.A. Influence of drying method on the material properties of nanocellulose I: Thermostability and crystallinity. Cellulose 2013, 20, 2379-2392. [CrossRef] 
31. Piskorz, J.; Radlein, D.S.A.G.; Donald, S.S.; Czernik, S. Pretreatment of wood and cellulose for production of sugars by fast pyrolysis. J. Anal. Appl. Pyrolysis 1989, 16, 127-142. [CrossRef]

32. Oh, S.Y.; Yoo, D.I.; Shin, Y.; Kim, H.C.; Kim, H.Y.; Chung, Y.S.; Park, W.H.; Youk, J.H. Crystalline structure analysis of cellulose treated with sodium hydroxide and carbon dioxide by means of $\mathrm{X}$-ray diffraction and FTIR spectroscopy. Carbohydr. Res. 2005, 340, 2376-2391. [CrossRef]

33. Gwon, J.G.; Lee, S.Y.; Doh, G.H.; Kim, J.H. Characterization of chemically modified wood fibers using ftir spectroscopy for biocomposites. J. Appl. Polym. Sci. 2010, 116, 3212-3219. [CrossRef]

34. Sehaqui, H.; de Larraya, U.P.; Liu, P.; Pfenninger, N.; Mathew, A.P.; Zimmermann, T.; Tingaut, P. Enhancing adsorption of heavy metal ions onto biobased nanofibers from waste pulp residues for application in wastewater treatment. Cellulose 2014, 21, 2831-2844. [CrossRef]

35. Zhu, C.; Soldatov, A.; Mathew, A.P. Advanced microscopy and spectroscopy reveal the adsorption and clustering of $\mathrm{Cu}$ (II) onto TEMPO oxidized cellulose nanofibers. Nanoscale 2017, 9, 7419-7428. [CrossRef]

36. Habibi, Y.; Chanzy, H.; Vignon, M.R. TEMPO-mediated surface oxidation of cellulose whiskers. Cellulose 2006, 13, 679-687. [CrossRef]

37. Socrates, G. Infrared and Raman Characteristic Group Frequencies, 3rd ed.; John Wiley \& Sons Ltd.: Chichester, UK, 2001; pp. 50-67.

38. Coseri, S.; Biliuta, G.; Zemljič, L.F.; Srndovic, J.S.; Larsson, P.T.; Strnad, S.; Kreže, T.; Naderi, A.; Lindstrom, T. One-shot carboxylation of microcrystalline cellulose in the presence of nitroxyl radicals and sodium periodate. RSC Adv. 2015, 5, 85889-85897. [CrossRef]

39. Clark, D.T.; Cromarty, B.J.; Dilks, A. A theoretical investigation of molecular core binding and relaxation energies in a series of oxygen-containing organic molecules of interest in the study of surface oxidation of polymers. J. Polym. Sci. Polym. Chem. Ed. 1978, 16, 3173-3184. [CrossRef]

40. Zhou, J.-H.; Sui, Z.-J.; Zhu, J.; Li, P.; Chen, D.; Dai, Y.-C.; Yuan, W.-K. Characterization of surface oxygen complexes on carbon nanofibers by TPD, XPS and FT-IR. Carbon 2007, 45, 785-796. [CrossRef]

41. Li, S.-S.; Wang, X.-L.; An, Q.-D.; Xiao, Z.-Y.; Zhai, S.-R.; Cui, L.; Li, Z.-C. Upon designing carboxyl methylcellulose and chitosan-derived nanostructured sorbents for efficient removal of $\mathrm{Cd}(\mathrm{II})$ and $\mathrm{Cr}(\mathrm{VI})$ from water. Int. J. Biol. Macromol. 2020, 143, 640-650. [CrossRef] [PubMed]

42. Smith, M.; Scudiero, L.; Espinal, J.; McEwen, J.-S.; Garcia-Perez, M. Improving the deconvolution and interpretation of XPS spectra from chars by ab initio calculations. Carbon 2016, 110, 155-171. [CrossRef]

43. Ariffin, H.; Nishida, H.; Shirai, Y.; Hassan, M.A. Highly selective transformation of poly[(R)-3-hydroxybutyric acid] into trans-crotonic acid by catalytic thermal degradation. Polym. Degrad. Stab. 2010, 95, 1375-1381. [CrossRef]

44. Kaiser, M.R.; Anuar, H.; Razak, S.B.A. Ductile-brittle transition temperature of polylactic acid-based biocomposite. J. Thermoplast. Compos. Mater. 2011, 26, 216-226. [CrossRef]

45. Kim, K.J.; Doi, Y.; Abe, H. Effect of metal compounds on thermal degradation behavior of aliphatic poly(hydroxyalkanoic acid)s. Polym. Degrad. Stab. 2008, 93, 776-785. [CrossRef]

(C) 2020 by the authors. Licensee MDPI, Basel, Switzerland. This article is an open access article distributed under the terms and conditions of the Creative Commons Attribution (CC BY) license (http://creativecommons.org/licenses/by/4.0/). 